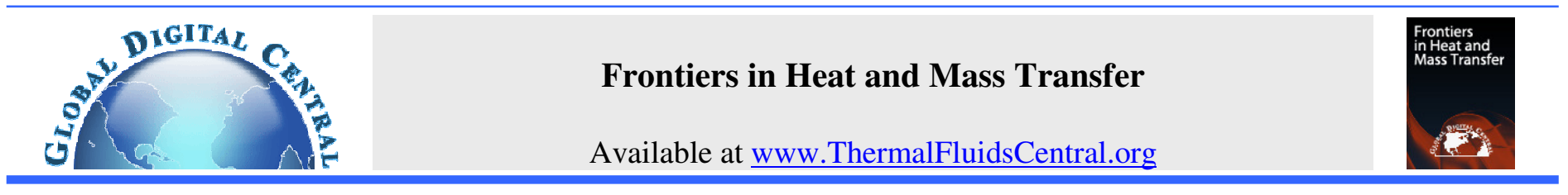

\title{
NUMERICAL SIMULATION ON CONDENSING FLOW OF WATER VAPOR OF WET NATURAL GAS INSIDE THE NOZZLE
}

\author{
Rongge Xiao ${ }^{\mathrm{a}}$, Wenbo Jin ${ }^{\mathrm{a}, *}$, Shicong $\mathrm{Han}^{\mathrm{b}}$, Rui $\mathrm{Li}^{\mathrm{a}}$, Xuewen $\mathrm{Cao}^{\mathrm{c}}$ \\ ${ }^{a}$ College of Petroleum Engineering, Xi'an Shiyou University, Xi'an / Shaanxi,710065, China \\ ${ }^{b}$ Sinopec Group Natural Gas Branch, Beijing, 100029, China \\ ${ }^{c}$ College of Pipeline and Civil Engineering, China University of Petroleum, Qingdao/Shandong, 266580, China
}

\begin{abstract}
Combines theories of gas dynamics, fluid dynamics and numerical heat transfer theory, the condensing flow characteristics of water vapor in wet natural gas within the Laval nozzle were studied. A mathematical model was developed to predict the spontaneous condensing phenomenon in the supersonic flows using the classical nucleation and droplet growth theories. The numerical approach is validated with the experimental data by using UDF and UDS modules in FLUENT software, which shows a good agreement between them, and showed that the mathematical model can better predict the parameter changes in the condensation process. The condensation characteristics of water vapor in the Laval nozzle are described in detail. The results show that the condensation process was a rapid variation of the vapor-liquid phase change both in the space and in time, the distribution of nucleation rate is restricted to a small area. The spontaneous condensation of water vapor will not appear immediately when the steam reaches the saturation state. Instead, it occurs downstream the nozzle throat, where the steam is in the state of supersaturation. The previous accumulation of Supersaturation has led to a nuclear process occurring in a very short time. The degree of supercooling was also dramatically reduced in this small area, and when it is below the supersaturation limitation, the nucleation process ceases to occur.
\end{abstract}

Keywords: Laval nozzle, Wet natural gas, Supersonic speed, Condensing flow.

\section{INTRODUCTION}

The main component of natural gas exploit from gas well is methane, and a certain amount of water and heavy hydrocarbon. The presence of water and heavy hydrocarbon will cause serious harm to gas gathering and transportation. In order to ensure safe storage and transportation of natural gas, dehydration treatment is required for wet gas. Natural gas is usually produced from the wellhead with very high pressure, through expansion to cool and depressurize at certain condition, make water vapor condense from wet gas, and with gravity separation, cyclone separation, filtration or other method to separate it from gas.

Supersonic cyclone separator is the device that realizes the separation of gas and liquid by condensing with temperature decreased when the wet natural gas flows through the Laval nozzle. The core of supersonic hydrocyclone separation technology of wet gas is to use the low temperature and low pressure condition to condense water and heavy hydrocarbons. In 1942, Oswatisch (Ding et al., 2014) carried out a one-dimensional numerical simulation of the condensation flow of the wet steam in the Laval nozzle, and the simulated results were in good agreement with the experimental data. However, it is relatively late to use supersonic cyclone to separate the gas and liquid (Hill, 1966; Holten et al., 2005; Cao et al., 2008). The wet gas is at low temperature and low pressure condition through the expansion after getting into the Laval nozzle, and reaches sound velocity at the throat position, which increases supercooling and supersaturation, when the supercooling degree reaches to a certain level, condensation occurs. To effectively separate water vapor and heavy hydrocarbon, it must ensure that the droplet radius of Laval nozzle at the outlet is within a certain range. If the droplet radius is too small, the droplets will go downstream with gas, on the contrary it will affect the cyclone effect as its large inertia force.
The condensation phenomenon of vapor plays an important role in various industries, such as the steam flow and water vapor in nozzles, turbines, ejectors, thermos-compressors and supersonic separators (Wróblewski et al., 2016; Keisari et al., 2016; Patel et al., 2015; Sharifi et al., 2013; Wen et al., 2016; Yang et al., 2017). The initial research of gas condensation flow in the nozzle is mainly based on the condensation of a single component. The study of multi-component research began in the last 20 years, represented by Eindhoven in the Netherlands and the Ohio University in the United States. They built a perfect experimental system, the two-component and multi-component gas condensation parameters were studied, and achieved some results (Kalikmanov et al., 1995; Kalikmanov, 2006). Theoretical and experimental studies have been conducted for the condensation process in supersonic flows, focusing on the nucleation theory, droplet size, latent heat (Moses, 1977; Girshick et al., 1990; Dykas et al., 2014; Ding et al., 2014). Numerical simulations have been performed to predict the condensing flow with the development of the computational fluid dynamics (CFD) for several decades (Labetski et al., 2004; Jiang et al., 2016). Luijten (Luijten et al., 1999) studied the carrying gascondensable and proposed the theory of carrying gas influencing factors. The condensation and flow patterns of water vapor, nonane and pentane were studied when helium and nitrogen were used as carriers. The effects of gas carrying on the nucleation of condensable gas were studied by using the classical nucleation theory and semiempirical nucleation theory proposed by Kalikmanov and Van Dongen, respectively. Peeters (Peeters, 2002) studied the nucleation and droplet growth characteristics of a three-component mixture of nonane-water vapor-methane. And the effect of carrying gas on the nucleation process was studied, and the possibility of heterogeneous nucleation in the three-component mixture was discussed. The flux matching method

*Corresponding Author. E-mail: jinwb678@163.com. 
was used to describe the growth of droplets after the formation of droplets in the carrier gas. And the nucleation and droplet growth processes of two-component and multi-component steam were compared by using the Nucleation Pulse Expansion Tube. Robert (McGraw et al., 2008) analyzed the condensation law of the multicomponent system, and studied the condensation law of ammonia mixed with sulfuric acid and water vapor. Some researchers (Looijmans et al., 1995) measured the condensation of nonane and methane mixed gases under different pressures in the c condensation pulsating expansion tube, and believed that the presence of methane significantly affected the condensation process.

White and Young predicted the condensing process using Eulerian/Lagrangian and time-marching methods (White et al., 1993). Gerber (Gerber et al., 2002) developed the Eulerian/Lagrangian and Eulerian/Eulerian two-phase models for predicting the condensation flow with the classical nucleation theory. The effects of friction factor on the condensation flows in the Laval nozzles were performed using the single fluid model (Jiang et al., 2009). Two-dimensional simulation of the condensing steam was calculated in converging-diverging nozzles using a Jameson style finite volume method on an unstructured and adaptive triangular mesh (Simpson et al., 2005). Some researches (Xiao et al., 2007; Yang et al., 2009) described a conservative twodimensional compressible numerical model for the non-equilibrium condensing of the steam flow based on the classical nucleation theory and the Virial-equation of state. The effect of the expansion rate on the steam condensing flow through a converging-diverging nozzle was studied numerically (Nikkhahi et al., 2010). The steam condensing flow was modeled through the Laval nozzles at low and high inlet pressures by means of the single-fluid model (Mahpeykar et al., 2011; Shooshtari et al., 2013; Dykas et al., 2011). The Eulerian/Eulerian approach was adopted for modeling the condensing steam flow, and the simulation was conducted on the commercial ANSYS FLUENT platform (Yousif et al., 2013).

The condensation phenomenon of water vapor in supersonic flows is still not understood very well as a result of the complex phase change process. Especially, the numerical simulation depends on various nucleation theories and droplet growth models. To ensure the preferable separation effect of the separator, it is necessary to study the flow phenomena of the gas condenses in Laval nozzle and explore affecting factors of condensation flow parameters inside the nozzle. In this paper, the double fluid model is developed to predict the spontaneous condensing phenomenon in the Laval nozzle. Based on the mathematical model of water vapor condensation flow contained in wet gas, FLUENT software is used to simulate and verify the condensation of water vapor in the nozzle under high pressure. The modified internally consistent classic nucleation theory and Gyarmathy's droplet growth model are employed to perform the simulation cases. The numerical approach is validated with experimental data. The condensation process of water vapor of wet natural gas in the nozzle is numerically analyzed in detail, including the nucleation rate, supercooling degree, supersaturation, droplet numbers, droplet radius and humidity in the nozzle, which have a certain guiding significance on parameter settings of supersonic cyclone separator.

\section{MATHEMATICAL MODEL OF SUPERSONIC FLOW CONDENSATION WITHIN NOZZLE}

The core problem is the coupling of the gas-liquid two-phase flow in the description about the supersonic condensation flow in nozzle, the condensate flow model commonly used now can be concluded to two types: the single-fluid model and the two-fluid model (Menter,1994; Patankar et al.,1972; Wegener et al.,1958).

The single-fluid model is a model that put the wet vapor mixture consisted by gas and liquid phase as one kind of medium. The two-fluid model solves the gas phase and liquid phase respectively, the source phase is added in gas phase and liquid phase control equation set, which represents mass transfer, momentum and energy exchange between gas phase and liquid phase. During the condensation flow process in the nozzle, droplet exists in the form of dispersed phase, which can be regarded as dispersed phase and can also be seen as continuous phase, and the number, size and distribution of droplets are difficult to be predicted, therefore, it is very difficult to derive liquid control equations exactly fits reality. However, the reality is the distribution of droplet size meets certain statistical regularity, thus the concept of average number can be used to describe the distribution of droplet. The researchers (Fei et al., 2008) assumed that there is no velocity slip between liquid and vapor phases, inferred the gas phase speed control equation and the conservative Euler equations describes droplet distribution. In this paper, double fluid model is built to simulate the flow condensation phenomenon of water vapor in wet gas inside the nozzle, in the establishment and solving of equation using related function of calculation software FLUENT to establish the mathematical model.

\subsection{Mathematical model modeling}

When the two phase flow control equations of a supersonic nozzle are determined, the following assumptions are usually adopted: (1) there is no heat exchange between the fluid and the outside, and the system is in an adiabatic condition; (2) the flow of gas and liquid in the nozzle can be considered as compressible flow; (3) the thermodynamic properties of the flow media are continuous in the process of flow; (4) the droplets formed are incompressible small spheres, in the range of continuous flow; (5) there is no collision between droplets in the flow process; (6) the time required for nucleation is very short, and the number of droplet is unchanged after spontaneous nucleation; (6) the gas contains no foreign impurity; (7) no external electric field or magnetic field interference.

\subsubsection{Control Equations}

(1) Gas phase control equations

By using software FLUENT, gas phase control equation provided in the description of the quality of the gas phase equation, momentum equation and energy equation, and added in the equation due to the influences of liquid source phase.

$$
\begin{aligned}
& \frac{\partial \rho_{g}}{\partial t}+\frac{\partial}{\partial x_{j}}\left(\rho_{g} u_{j}\right)=S_{m} \\
& \frac{\partial}{\partial t}\left(\rho_{g} u_{i}\right)+\frac{\partial}{\partial x_{j}}\left(\rho_{g} u_{j} u_{i}\right)=-\frac{\partial p}{\partial x_{i}}+\frac{\partial}{\partial x_{j}}\left[\mu \left(\frac{\partial u}{\partial x_{j}}\right.\right. \\
& \frac{\partial}{\partial t}\left(\rho_{g} h\right)+\frac{\partial}{\partial x_{j}}\left(\rho_{g} u_{j} h\right)=\frac{\partial}{\partial x_{j}}\left(\lambda \frac{\partial T}{\partial x_{j}}\right)+S_{h} \\
& S_{m}=-m_{v} ; \quad S_{h}=m_{v} h_{\mathrm{lg}} ; \quad S_{u}=u m_{v} \\
& m_{v}=I \rho_{v} \frac{4 \pi r_{c}{ }^{3}}{3}+N_{b} \rho_{v} 4 \pi r^{2} \frac{d r}{d t}
\end{aligned}
$$$$
\frac{\partial}{\partial t}\left(\rho_{g} u_{i}\right)+\frac{\partial}{\partial x_{j}}\left(\rho_{g} u_{j} u_{i}\right)=-\frac{\partial p}{\partial x_{i}}+\frac{\partial}{\partial x_{j}}\left[\mu\left(\frac{\partial u_{j}}{\partial x_{j}}+\frac{\partial u_{i}}{\partial x_{j}}-\frac{2}{3} \frac{\partial u_{j}}{\partial x_{j}}\right)\right]+\Delta \rho_{g} g_{i}+S_{u}
$$

\section{(2) Liquid phase control equations}

The state parameters of liquid phase are described in terms of the number of droplets and the average radius, which can be obtained according to the general form of the control equation:

$$
\begin{aligned}
& \frac{\partial N_{b}}{\partial t}+\frac{\partial}{\partial x_{j}}\left(N_{b} u_{P j}\right)=J \\
& \frac{\partial\left(\rho_{l} Y\right)}{\partial t}+\frac{\partial}{\partial x_{j}}\left(\rho_{l} Y u_{p j}\right)=\rho \dot{m}
\end{aligned}
$$

After calculated the number of liquid droplets and the gas humidity, droplet radius can be calculated according to the following relational expression:

$$
r=\sqrt[3]{3 Y /\left(4 \pi \rho_{l} N_{v}\right)}
$$

(3) Turbulence equations

Due to the failure to take into account the slip of the gas and liquid 
phases, it is considered that the liquid droplets produce no effect on the turbulence of the liquid phase and only consider the gas phase turbulence equation. Within several turbulence models in FLUENT, the zero equation and the first equation has faster calculation speed, but relatively low accuracy; Although the Reynolds stress equation has characteristic of high calculation accuracy, its workload is huge, the computation speed is slower. The second equation model has advantages as high computational precision, qualified for engineering requirements, and simultaneously meets the limits load computer could sustain, therefore has been widely distributed in engineering calculations. The most common in the second equation model is standard $k-\varepsilon$ model, which based on the assumption that the turbulence direction is isotropic, in some region not satisfy the isotropic condition, will the equation leads to large calculation error, such as near-wall region and region with adverse pressure gradient. Yakhot and Orszag proposed to RNG $k-\varepsilon$ model (Yakhot V, Orszag S A., 1992), solve the above disadvantages of in 1986, RNG $k-\varepsilon$ model has a wider adaptability and accuracy than the original standard model. For high speed condensation inside the nozzle flow phenomena, using the RNG $k-\varepsilon$ model can be ideal computational accuracy and speed.

\subsubsection{Gas station equations}

Before condensing in the nozzle, the vapor is under saturation. Thermodynamic equilibrium state parameters can no longer be applied to the calculation. At relatively low temperature and low pressure environment, the ideal gas state equation is unable to use. In this case Young (Young, 1988) proposed Virial state equation suitable for wet vapor, which is expressed as follows:

$P_{v}=\rho_{v} R_{v} T_{v}\left(1+B \rho_{v}+C \rho_{v}^{2}+\cdots\right)$

\subsubsection{Surface Tension}

The existence of surface tension makes the droplet surface area decreases, equivalent to overcome the work of new molecule join and increase the surface area. Gibbs free energy on the droplet surface has direct relationship with the droplet surface area size and surface tension, the exist of droplet surface tension resist the droplet surface area to become larger, inhibit the growth of droplets, therefore in many influencing factors the surface tension is the most important in the condensation process. Surface Tension Model used is LD fitting model (Labetski et al., 2004):

When $T \geq 250.0 K$

$\sigma^{L D}(T)=(76.1+0.155(273.15-T)) \times 10^{-3}[\mathrm{~N} / \mathrm{m}]$

When $T<250.0 K$

$\sigma^{L D}(T)=8.52 \times 10^{-2}-3.54236 \times 10^{-4} T+3.50835 \times 10^{-6} T^{2}[\mathrm{~N} / \mathrm{m}]$

2.1.4 Nucleation and droplet growth mode

The classical ICCT model is been chosen in some literatures (Young, 1988):

$I_{I C C I}=\frac{1}{S} \frac{\rho_{v}^{2}}{\rho_{l}}\left(\frac{2 \sigma}{\pi m_{v}^{3}}\right)^{1 / 2} \exp \left(-\frac{4}{27} \frac{\theta^{3}}{(\ln S)^{2}}+\theta\right)$

Droplet growth model which adopted is model presented by Gyarmathy (Gyarmathy, 1982; Lamanna, 2000) and modified by Young(Young, 1988):

$$
\begin{aligned}
& \frac{d r}{d t}=\frac{\lambda_{v}}{\rho_{l} h_{\mathrm{lg}}} \frac{\left(T_{s}-T_{v}\right)\left(1-\frac{r_{c}}{r}\right)}{r\left(\frac{1}{(1+2 \beta K n)}+3.78(1-\delta) \frac{K n}{\operatorname{Pr}_{v}}\right)} \\
& \delta=\frac{R_{v} T_{s}}{h_{\mathrm{lg}}}\left[\alpha-0.5-\frac{2-q_{c}}{q_{c}}\left(\frac{\gamma+1}{2 \gamma}\right) \frac{c_{p, v} T_{s}}{h_{\mathrm{lg}}}\right]
\end{aligned}
$$

\subsection{Implementation of the numerical simulation calculation model}

This article will use custom functions provided by the FLUENT as UDF (User-Defined Function), UDS (User-Defined Scalars) and UDRGM (User-Defined Real Gas Model) to achieve gas-liquid phase control equation and nucleation and droplet growth model.

\subsubsection{User-defined functions UDF and user-defined scalar UDS}

UDF, User Defined Function, is computer program written by the users themselves, must be written in $\mathrm{C}$ language, and must abide by certain written rules. In this program, two macro (DEFINE-AJUST and DEFINE-SOURCE) are used, the nucleation rate, droplet growth rate, degree of supercooling, degree of supersaturation and droplet surface tension parameter does not exist in the software is defined in the DEFINE-AJUST, and is stored in UDM (User-Defined Memory), in each iteration, the software will use these parameters, traverse each grids and meshes to calculate. In the source phase definition macro DEFINE-SOURCE, it defines the source phase of mass, momentum and energy sources due to the presence of the droplets. When calculated, these source phases are added to gas phase control equation.

In the liquid phase control equations, the droplets number and humidity is achieved by UDS, user-defined scalar. In FLUENT, UDS is usually used to solve similarly the convection-diffusion equation and flow field coupling, can be used to describe phenomenon as mass transfer, transport, etc. Convection diffusion equation usually contains convection term, diffusion, and source stationary phase, corresponding to different macros.

\subsubsection{User-defined real gas model UDRGM}

FLUENT does not provide Virial state equation, the software provides user-defined real gas model, and it must comply with $\mathrm{C}$ language programming rules. After programming completed, need to compile the $\mathrm{C}$ program, and establish shared document library. After the document library established, a specific command statement can be entered to call Virial real gas state equation.

\section{VALIDATION AND ANALYSIS OF MATHEMATICAL MODELS}

Geometry parameters and the experimental data used in the examples are taken from Laval nozzle experiments of Moses \& Stein(Moses, 1977), the nozzle geometry is shown in Figure 1. Nozzle throat is at $0.0822 \mathrm{~m}$, size $0.01 \mathrm{~m} \times 0.01 \mathrm{~m}$; The subsonic section is constituted by arc of radius $53 \mathrm{~mm}$, while transonic and supersonic section with arc of radius $686 \mathrm{~mm}$. Initial conditions of calculation model are: inlet pressure of $43027 \mathrm{~Pa}$, inlet temperature of $366 \mathrm{~K}$, various physical properties of water vapor can be solved by user-defined real gas state equation. The degree of subcooling and supersaturation, nucleation rate, droplet radius and other parameters concerned in the research can be calculated by UDF adding to FLUENT.

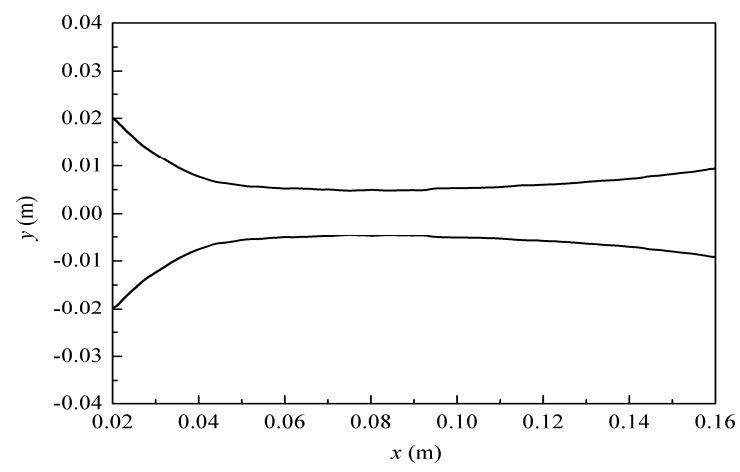

Fig. 1 Geometry and size of Laval nozzle in Moses \& Stein's experiment 


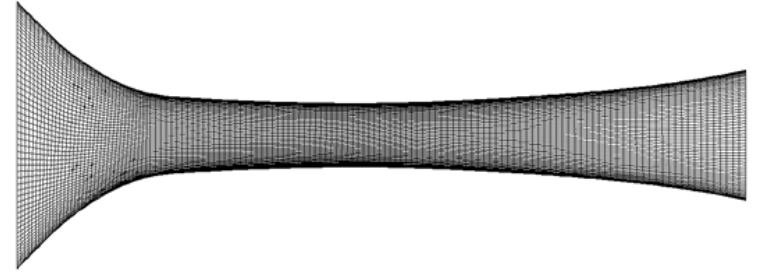

Fig. 2 Mesh of the computational domain

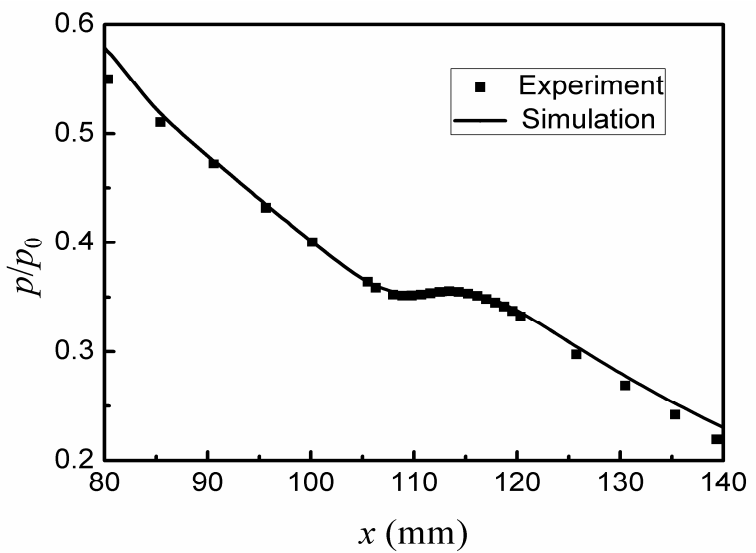

Fig. 3 Experiment and simulation results of static pressure ratio at the central line of the Laval nozzle

Figure 3 shows the various status of value calculation under above operating condition and static pressure ratio (the ratio of local static pressure and inlet static pressure, $\mathrm{p} / \mathrm{p}_{0}$ ) in the experiment along the central line of the Laval nozzle. The pressure is gradually decreasing on the center line of the nozzle, when condensation occurs, there is a pressure curve first decreased then process the condensation process releases latent heat of the heating gas stream produced condensation wave, numerical calculation is better captured this process, and the calculated results fit with the experimental values.

\subsection{Grid-independent and time-step independence}

The mesh density is one of the key factors that determine the accuracy of the numerical simulation. In order to justify the numerical simulation carried out, but also it is need to prove that the number of meshes and numerical simulation model and simulation time step when there is no relationship, which is independent of the grid to validate the model time step and independence. Three different densities of the structural meshes are used to test the mesh independence. The condensation parameters, such as, nucleation rate, humidity and Droplet radius are selected to evaluate the effect of the mesh density on the condensation simulation. Table 1 and table 2 give a comparison respectively of the number of droplet, nucleation rate, humidity and droplet radius which the grid number and the time step are different.

Table 1 data were collected from the time of $10 \mathrm{~s}$, the number 23040 for the control grid, grid computing grid numbers increase and decrease the number of errors when the main coagulation parameters. When the number of changes can be found in the grid, the main parameters of the error were relatively small. The data in Table 2 are used in time of $15 \mathrm{~s}$, when the grid number 23040 in $0.00001 \mathrm{~s}$ as control can be found with different time steps when minimal effect on coagulation parameters. Through the two tables well validated numerical simulation of mesh-independent and time-step independence. Therefore, the mesh system is used to conduct our simulations considering the computing accuracy and efficiency.

\subsection{Parametric analysis of water vapor condensation}

Figure 4 shows temperature distribution in nozzle and a partial temperature gradients at the central line of the Laval nozzle, it shows that the temperature of the vapor is continuously decreasing after entering the nozzle, and condensation occurs before the temperature dropped to $294 \mathrm{~K}$, follows by the evaporation release of latent heat, the temperature fluctuates in the condensation zone, rises to $321 \mathrm{~K}$, after the nucleation stage ends, the growing stage of droplets caused temperature changes is much smaller than that of the nozzle, so the temperature continues dropping.
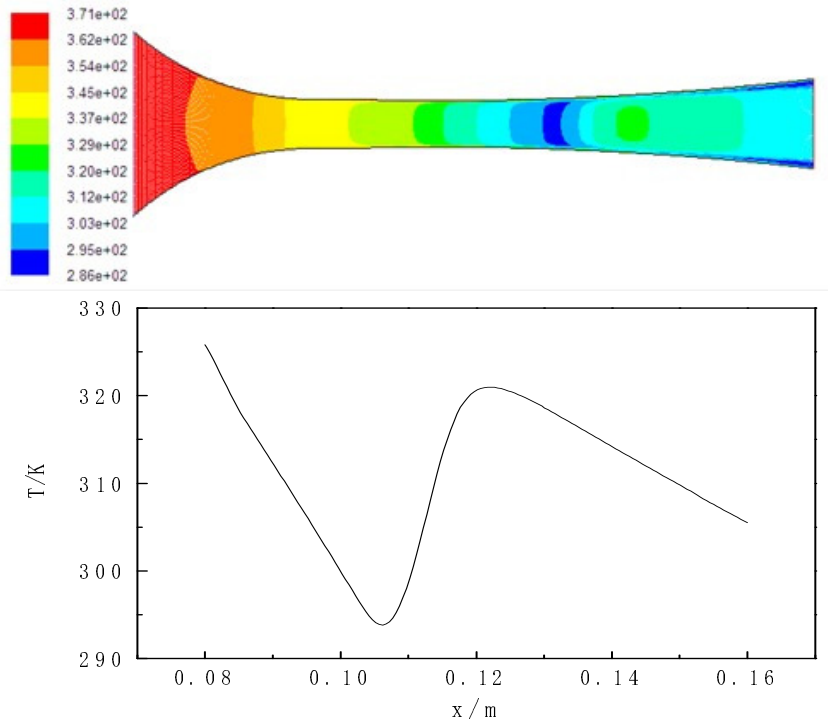

Fig. 4 Temperature distribution in nozzle and at the central line of nozzle
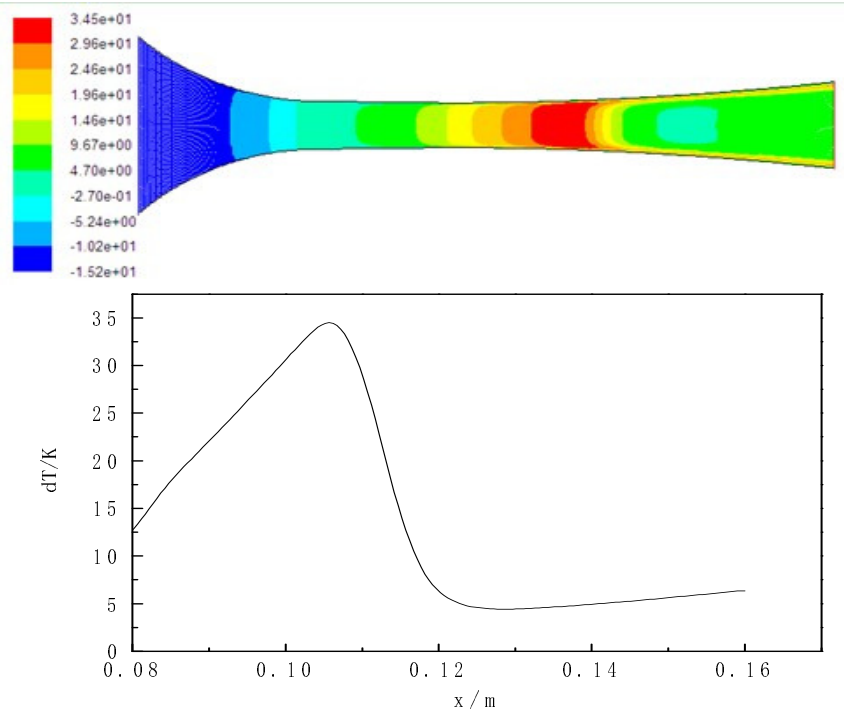

Fig. 5 Degree of supercooling (dT) in nozzle and at the central line of nozzle

Figure 5 shows degree of supercooling in nozzle and the change of the local degree of supercooling at the central line of the Laval nozzle, We can see that the supercooling degree increases constantly along with the vapor expansion, and it rapidly rises to the peak value of about 34.5 $\mathrm{K}$ in this case. The results show that the latent heat of the vapor is released to heat into the vapor phase during the spontaneous condensation, leading to the jump of the condensing parameters. Vapor temperature and pressure are increased resulting in the degree of supercooling tends to suddenly decrease from $34.5 \mathrm{~K}$ to $4.5 \mathrm{~K}$, which means that the condensation process has finished.

Figure 6 shows degree of supersaturation in nozzle and changes at the central line of local over-saturation, with the expansion will be the degree of supersaturation increases maximum 6.6 point position, nucleation occurs at this time, the degree of supersaturation in a small area decreased rapidly, and finally stabilized at around 1.3. Figure 7 
shows humidity distribution in nozzle and a partial variation of humidity at the central line of the Laval nozzle, humidity can see the position of the nozzle within the scratch and supersaturation peak positions coincide. Before a larger part of the slope of the curve, because a large number of nucleation phase droplets in a very short time to form, more severe changes in humidity. Subsequently growth phase droplets were a relatively long stage and humidity changes significantly inferior to the nucleation stage.

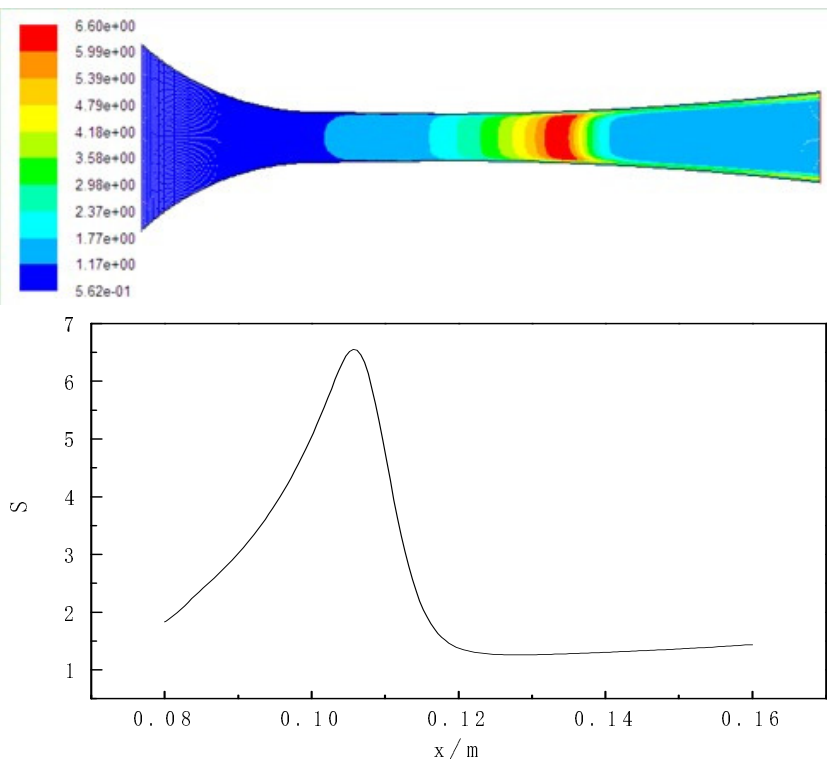

Fig. 6 Degree of supersaturation in nozzle and at the central line of nozzle
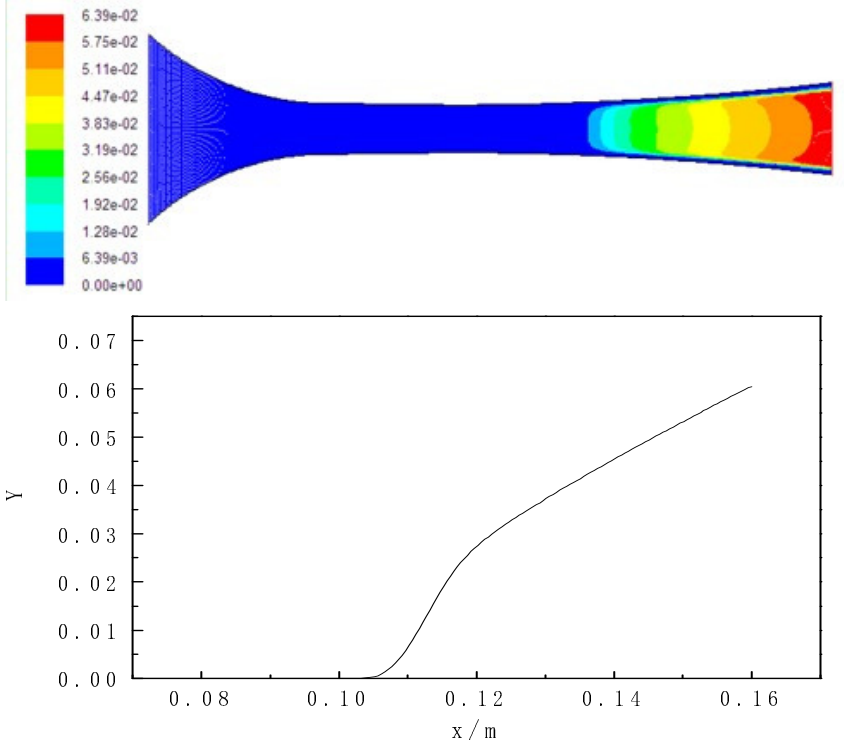

Fig. 7 Humidity distribution in nozzle and at the central line of nozzle

Figure 8 shows droplet number distribution in nozzle and the local distribution of droplet number at the central line of the Laval nozzle, the number of droplets within extremely time from zero to $3.8 \times 10^{19} / \mathrm{m}^{3}$ due to the sharp process of the vapor nucleation. Then, the steam is almost obtained to the equilibrium state because of the decrease of the supercooling degree. At that moment, no new condensation nucleation appear and the droplet number remains effectively stabilized.

Figure 9 shows nucleation rate distribution in nozzle and partial nucleation rate distribution at the central line of the Laval nozzle, it can be seen from the figure the distribution of nucleation rate is only limited to a small area, with a maximum of $7.2 \times 10^{23} / \mathrm{m}^{-3} \mathrm{~s}^{-1}$. The spontaneous condensation of water vapor will not appear immediately when the steam reaches the saturation state. Supersaturation accumulated before prompting the nucleation process in the a very short time of occurrence, the degree of supercooling is also drastically reduced within this small range, and when it is below the saturation limit, the nucleation process ceases to occur. Instead, it occurs further downstream the nozzle throat, where the steam is in the state of supersaturation. In this condition, the steam is in an extremely non-equilibrium thermodynamic state, leading to the occurrence of the spontaneous condensation in a very short time, which can be observed in Figure 9.

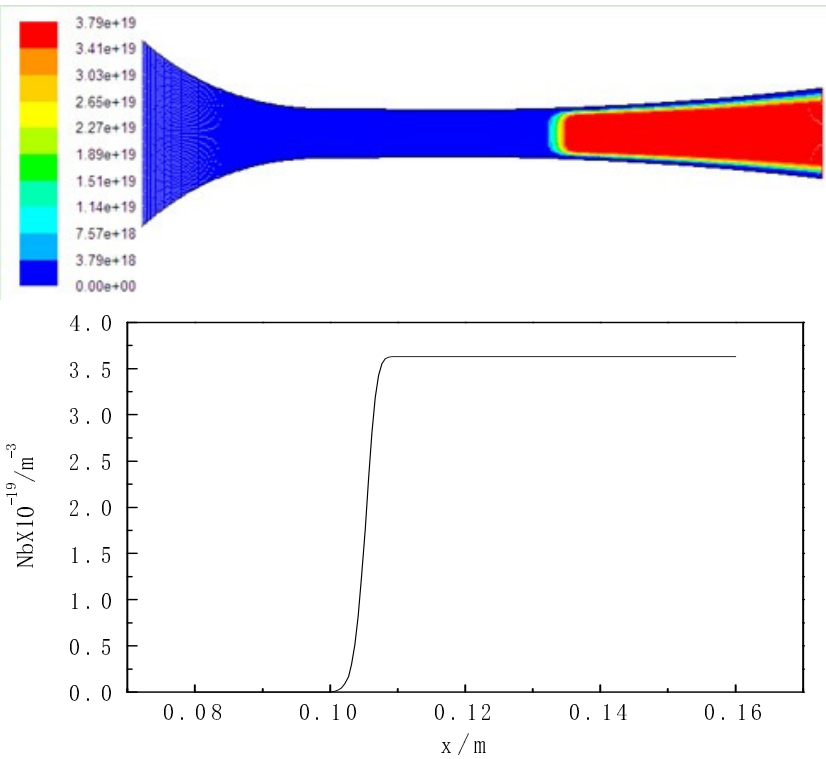

Fig. 8 Droplet number $(\mathrm{Nb})$ distribution in nozzle and at the central line of nozzle

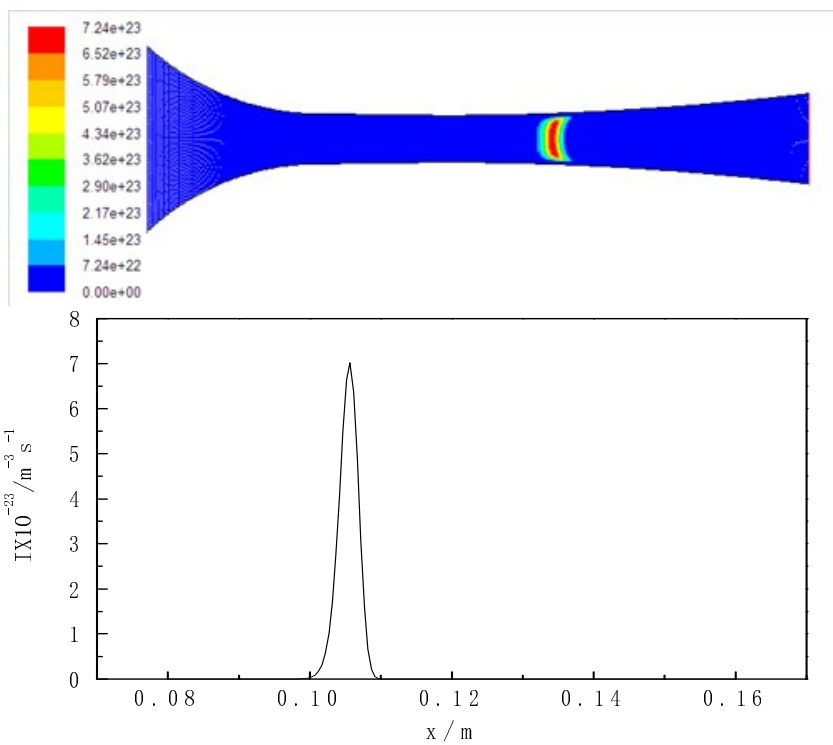

Fig. 9 Nucleation rate distribution in nozzle and at the central line of nozzle

Figure 10 shows droplet radius distribution in nozzle and partial change of the droplet radius at the central line of the Laval nozzle. After a certain position over saturation limit is reached, the droplet radius has reached the critical radius, since the number of the initial stages of small droplets small droplet radius, releasing latent heat sufficient to change the temperature and pressure, so the droplet radius does not change obviously. Since then a large number of droplet formation and growth of droplet radius gradually becomes large. 
Table 1 Error of parameters at different number of meshes

\begin{tabular}{|c|c|c|c|c|c|c|c|c|}
\hline $\begin{array}{c}\text { The number } \\
\text { of meshes }\end{array}$ & Droplet number & error & Nucleation rate & error & humidity & error & Droplet radius & error \\
\hline 23040 & $3.74 \times 10^{19}$ & -- & $7.24 \times 10^{23}$ & -- & 0.0639 & -- & $7.38 \times 10^{-9}$ & -- \\
\hline 11904 & $3.73 \times 10^{19}$ & $-0.3 \%$ & $7.28 \times 10^{23}$ & $0.5 \%$ & 0.0636 & $-0.9 \%$ & $7.57 \times 10^{-9}$ & $2.6 \%$ \\
\hline 40161 & $3.70 \times 10^{19}$ & $-1.2 \%$ & $7.20 \times 10^{23}$ & $-0.5 \%$ & 0.0630 & $-2.0 \%$ & $7.44 \times 10^{-9}$ & $0.8 \%$ \\
\hline
\end{tabular}

Table 2 Error of parameters at different time step

\begin{tabular}{|c|c|c|c|c|c|c|c|c|}
\hline Time Step & Droplet number & error & Nucleation rate & error & humidity & error & Droplet radius & error \\
\hline $0.00001 \mathrm{~s}$ & $3.74 \times 10^{19}$ & -- & $7.24 \times 10^{23}$ & -- & 0.0639 & -- & $7.38 \times 10^{-9}$ & -- \\
\hline $0.0001 \mathrm{~s}$ & $3.73 \times 10^{19}$ & $-0.3 \%$ & $7.25 \times 10^{23}$ & $0.14 \%$ & 0.0637 & $-0.3 \%$ & $7.37 \times 10^{-9}$ & $-0.14 \%$ \\
\hline $0.001 \mathrm{~s}$ & $3.73 \times 10^{19}$ & $-0.3 \%$ & $7.25 \times 10^{23}$ & $-0.13 \%$ & 0.0636 & $-0.5 \%$ & $7.37 \times 10^{-9}$ & $-0.14 \%$ \\
\hline
\end{tabular}
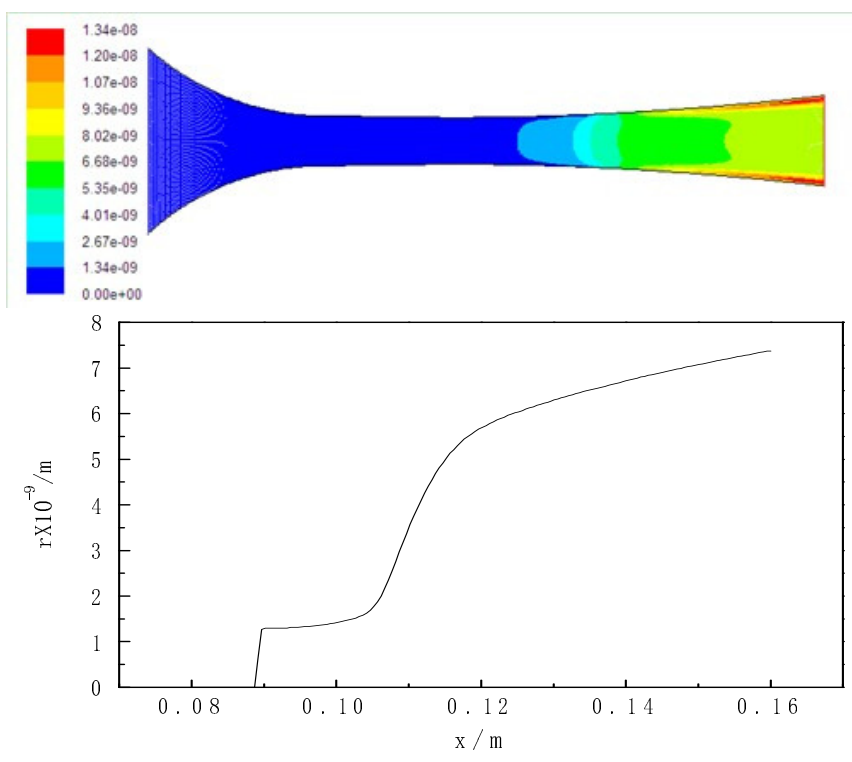

Fig. 10 Droplet radius distribution in nozzle and at the central line of nozzle

\section{CONCLUSIONS}

The condensation process of water vapor in wet natural gas within the Laval nozzle is simulated numerically, the two-fluid mathematical model of condensation flow is established with control equations of liquid phase and gas phase, and the nucleation and droplet growth theories. Through nucleation and droplet growth model, the mass increase of liquid phase and the decrease of gas phase are obtained. The mathematical model is applied to solve the related condensation parameters, including nucleation rate, droplet growth rate, undercooling, supersaturation and condensation droplet radius and other important parameters. The numerical simulation is verified, and the independence of grid and time step is verified, which proves the stability of the mathematical model.

The obtained pressure drop curve is consistent with the curve in the literature, which verifies the correctness of the mathematical model. The variation rules and causes of condensation parameters are analyzed, the results show that the latent heat is released to heat into the vapor phase during the spontaneous condensation, leading to the jumping of the condensing parameters. The degree of supercooling can reach a maximum value of about $34.5 \mathrm{~K}$ and correspondingly the spontaneous condensation occurs in a very short time. The droplet numbers also rapidly rise from zero to $3.8 \times 10^{19} / \mathrm{m}^{3}$ due to the sharp process of the vapor nucleation in a very short time. Then, the droplet radius also begin to increase continuously till the nozzle outlet as a result of the supercooling degree at about $4.5 \mathrm{~K}$. The rules for supersonic parameter Settings and separation effect prediction of cyclone separator have a certain guiding significance.

\section{ACKNOWLEDGEMENT}

This work was supported by the Special Funding Project of Shaanxi Province Industrial Science and Technology Project (NO. 2015GY094) and Xi'an Petroleum University Youth Science and Technology Innovation Fund (NO. 2015BS011), so grateful here.

\section{NOMENCLATURE}

$u \quad$ axial direction velocity, $\mathrm{m} / \mathrm{s}$;

$h$ the latent heat of vaporization, $\mathrm{kJ} / \mathrm{kg}$

$T \quad$ actual temperature, $\mathrm{K}$

$S_{m} \quad$ quality transfer source phase from the gas phase to the liquid

$S_{h} \quad$ energy transfer source phase from the gas phase to the liquid

$S_{u} \quad$ momentum transfer source phase from the gas phase to the liquid

$m_{v} \quad$ a unit time per unit volume of condensed vapor quality, $\mathrm{kg} /\left(\mathrm{s} \cdot \mathrm{m}^{3}\right)$

I the number of droplets wet vapor condensation nuclei per unit time per unit volume formed Serve nucleation rate, $\mathrm{m}^{-3} \mathrm{~s}^{-1}$

$r_{c} \quad$ critical condensation radius of water vapor molecules, $\mathrm{m}$

$N_{b} \quad$ the number of small droplets along the axis of the distribution of gas, $\mathrm{m}^{-3}$

$r \quad$ the droplet radius, $m$

$u_{p j} \quad$ the average velocity in the axial direction, $\mathrm{m} / \mathrm{s}$

$Y$ the mass fraction of water vapor in the gas or gas humidity, $Y=\frac{m_{\mathrm{H}_{2} \mathrm{O}(\mathrm{g})}}{m_{\mathrm{H}_{2} \mathrm{O}(\mathrm{g})}+m_{\mathrm{CH}_{4}}}$, dimensionless

$\dot{m} \quad$ the coagulated mass rate, $\mathrm{kg} / \mathrm{s}$

$N_{v} \quad$ the unit volume of the vapor kinetic factor, dimensionless

$P_{v} \quad$ wet vapor pressure, $\mathrm{Pa}$

$R_{v} \quad$ wet vapor gas constant, $\mathrm{J} /(\mathrm{kg} \cdot \mathrm{K})$;

$T_{v} \quad$ wet vapor temperature, $\mathrm{K}$

$B, C \quad$ the Virial coefficient.

$I_{I C C T} \quad$ nucleate rate in classic ICCT model, $\mathrm{m}^{-3} \mathrm{~s}^{-1}$

$S \quad$ the degree of supersaturation of vapor, dimensionless;

$K_{B} \quad$ the Boltzmann constant, $\quad K_{B}=1.3806505 \times 10^{-23}, \mathrm{~J} / \mathrm{K}$

$V_{m l} \quad$ liquid phase molecular volume, $\mathrm{m}^{3}$

$T_{s} \quad$ given pressure supersaturated vapor temperature, $\mathrm{K}$

$K n$ namely the Kundsen number, represents the different situations of vapor molecules collide with droplet 
$L$ the mean free path of gas molecules, $L=\frac{2 \mu \sqrt{R_{v} T_{v}}}{p_{v}}, \mathrm{~m}$

$\operatorname{Pr}_{v} \quad$ the vapor Prandtl number, dimensionless number

$q_{c} \quad$ the condensation coefficient, $q_{c} \approx 1$

$c_{p, v} \quad$ the vapor specific heat at constant pressure, $\mathrm{kJ} /(\mathrm{kg} \cdot \mathrm{K})$

Greek Symbols

$\rho_{g} \quad$ vapor phase density, $\mathrm{kg} / \mathrm{m}^{3}$

$\rho_{v} \quad$ wet vapor density, $\mathrm{kg} / \mathrm{m}^{3}$

$\rho_{l} \quad$ the liquid density, $\mathrm{kg} / \mathrm{m}^{3}$

$\sigma^{L D}$ the droplet surface tension in LD fitting model, $\mathrm{N} / \mathrm{m}$.

$\sigma \quad$ the droplet surface tension, $\mathrm{N} / \mathrm{m}$

$\theta$ the dimensionless surface tension, dimensionless

$$
\theta=\frac{\sigma \alpha_{0}}{K_{B} T}, \alpha_{0}=(36 \pi)^{\frac{1}{3}}\left(V_{m l}\right)^{\frac{2}{3}}
$$

$\lambda_{v} \quad$ vapor thermal conductivity, $\mathrm{W} /(\mathrm{m} \cdot \mathrm{K})$

$\beta \quad$ the relation coefficient of free collision zone radius and droplet radius in Lamanna model, generally $\beta=2$

$\mu \quad$ the dynamic viscosity coefficient of vapor, $\mathrm{kg} /(\mathrm{m} \cdot \mathrm{s})$

$\gamma \quad$ the specific heat ratio of vapor

$\phi \quad$ correction coefficient of droplet growth, generally $\phi=9$

\section{REFERENCES}

Ding H, Wang C, Chen C., 2014, "Non-Equilibrium Condensation of Water Vapor in Sonic Nozzle," Applied Thermal Engineering, 71(1): 324-334.

https://doi.org/10.1016/j.applthermaleng.2014.07.008

Hill, P. G., 1966, "Condensation of Water Vapor during Supersonic Expansion in Nozzle," Journal of Fluid Mechanics, 25(4): 593-620. https://doi.org/10.1017/S0022112066000284

Holten, V., D. G. Labetski, and M. E. H. Van Dongen., 2005, "Homogeneous Nucleation of Water between 200 and $240 \mathrm{~K}$ : New Wave Tube Data and Estimation of the Tolman Length," The Journal of chemical physics, 123 (10): 104505.

http://dx.doi.org/10.1063/1.2018638

Cao, X.W., Xiao, R.G., Du Y.J., Li, Z. D., Lin Z. H., 2008, "Study on the Phase Transition of High-Speed Natural Gas Flow in a Nozzle by Numerical Method," Journal of Xi'an Shiyou University (Natural Science Edition), 23(1): 56-60.

http://dx.doi.org/10.3969/j.issn.1673-064X.2008.01.012

Wróblewski W, Dykas S., 2016, "Two-Fluid Model with Droplet Size Distribution for Condensing Steam Flows," Energy, 106: 112-120. https://doi.org/10.1016/j.energy.2016.03.052

Keisari S J, Shams M., 2016, "Shape Optimization of Nucleating WetSteam Flow Nozzle," Applied Thermal Engineering, 103: 812-820. https://doi.org/10.1016/j.applthermaleng.2016.04.134

Patel Y, Patel G, Turunen S T., 2015, "Influence of Turbulence Modeling on non-Equilibrium Condensing Flows in Nozzle and Turbine Cascade," International Journal of Heat and Mass Transfer, 88: 165-180.

https://doi.org/10.1016/j.ijheatmasstransfer.2015.04.069

Sharifi N, Boroomand M, Sharifi M., 2013, "Numerical Assessment of Steam Nucleation on Thermodynamic Performance of Steam Ejectors," Applied Thermal Engineering, 52(2): 449-459.

https://doi.org/10.1016/j.applthermaleng.2012.12.003
Wen C, Yang Y, Walther J H, et al., 2016, "Effect of Delta Wing on the Particle Flow in a novel gas supersonic separator," Powder Technology, 304: 261-267.

https://doi.org/10.1016/j.powtec.2016.07.061

Yang Y, Wen C, Wang S, et al., 2014, "Numerical Simulation of Real Gas Flows in Natural Gas Supersonic Separation Processing," Journal of Natural Gas Science and Engineering, 21: 829-836.

https://doi.org/10.1016/j.jngse.2014.10.010

Yang Y., Wen C., 2017, "CFD Modeling of Particle Behavior in Supersonic Flows with Strong Swirls for Gas Separation," Separation and Purification Technology, 174: 22-28.

https://doi.org/10.1016/j.seppur.2016.10.002

Kalikmanov V I, van Dongen M E H., 1995, “Quasi-One-Component Theory of Homogeneous Binary Nucleation," Physical Review Engineering, 51(5): 4391. https://doi.org/10.1103/PhysRevE.51.4391

Kalikmanov V I., 2006, "Mean-Field Kinetic Nucleation Theory," The Journal of chemical physics, 124(12): 124505.

http://dx.doi.org/10.1063/1.2178812

Moses, G.A., 1977, "On the Growth of Steam Droplets Formed in the Laval Nozzle Using Both Static Pressure and Light Scattering Measurement," Journal of Fluids Engineering, 77(3): 311-322. http://dx.doi.org/10.1115/1.3448672

Girshick, S.L., Chiu, C., 1990, "Kinetic Nucleation Theory - a New Expression for the Rate of Homogeneous Nucleation from an Ideal Supersaturated Vapor," Journal of Chemical Physics, 93(2): 1273-1277. http://dx.doi.org/10.1063/1.459191

Dykas S, Majkut M, Strozik M, et al., 2015, "Experimental Study of Condensing Steam Flow in Nozzles and Linear Blade Cascade[J]. International Journal of Heat and Mass Transfer, 80: 50-57. https://doi.org/10.1016/j.ijheatmasstransfer.2014.09.010

Ding H, Wang C, Zhao Y., 2014, "An Analytical Method for Wilson Point in Nozzle Flow with Homogeneous Nucleating," International Journal of Heat and Mass Transfer, 73: 586-594.

https://doi.org/10.1016/j.ijheatmasstransfer.2014.02.036

Jiang, W., Bian, J., Liu, Y., Liu, Z., Teng, L., \& Geng, G., 2016, "Investigation of Flow Characteristics and the Condensation Mechanism of Ternary Mixture in a Supersonic Nozzle," Journal of Natural Gas Science and Engineering, 34, 1054-1061. https://doi.org/10.1016/j.jngse.2016.07.075

Luijten C C M, Peeters P, Van Dongen M E H., 1999, "Nucleation at High Pressure. II. Wave Tube Data and Analysis," The Journal of Chemical Physics, 111(18): 8535-8544.

http://dx.doi.org/10.1063/1.480194

Peeters P., 2002, "Nucleation and Condensation in Gas-Vapor Mixtures of Alkanes and Water," Ph.D. Thesis, Technische Universiteit Eindhoven.

https://doi.org/10.6100/IR559332

McGraw R., Zhang R., 2008, "Multivariate Analysis of Homogeneous Nucleation Rate Measurements Nucleation in the P-Toluic Acid/Sulfuric Acid/Water System," The Journal of Chemical Physics, 128(6): 064508.

http://dx.doi.org/10.1063/1.2830030 
Looijmans K N H, Luijten C C M, Van Dongen M E H., 1995, Binary Nucleation Rate Measurements of N-Nonane/Methane at high pressures," The Journal of Chemical Physics, 103(4): 1714-1717. http://dx.doi.org/10.1063/1.469742

White A J, Young J B., 1993, "Time-Marching Method for the Prediction of Two-Dimensional, Unsteady Flows of Condensing Steam," Journal of Propulsion and Power, 9(4): 579-587.

https://doi.org/10.2514/3.23661

Gerber A., 2002, "Two-Phase Eulerian/Lagrangian Model for Nucleating Steam Flow," Journal of Fluids Engineering, 124: 465-475. https://doi.org/10.1115/1.1454109

Jiang W M, Liu Z L, Liu H W, et al., 2009, "Influences of Friction Drag on Spontaneous Condensation in Water Vapor Supersonic Flows," Science in china series E: technological sciences, 52(9): 2653-2659. https://doi.org/10.1007/s11431-009-0121-5

Simpson D A, White A J., 2005, "Viscous and Unsteady Flow Calculations of Condensing Steam in Nozzles," International Journal of Heat and Fluid Flow, 26(1): 71-79.

https://doi.org/10.1016/j.ijheatfluidflow.2004.04.002

Yang, Y., Shen, S. Q., et al., 2008, "Numerical Simulation on Spontaneous Condensation in Supersonic Steam Flow," Journal of Engineering Thermophysics, 29(8): 1393-1396. http://dx.doi.org/10.3321/j.issn:0253-231X.2008.08.035

Xiao Q, Tsai H M, Papamoschou D., 2007, "Numerical Investigation of Supersonic Nozzle Flow Separation,” AIAA Journal, 45(3): 532. http://dx.doi.org/10.2514/1.20073

Yang Y, Shen S., 2009, "Numerical Simulation on Non-Equilibrium Spontaneous Condensation in Supersonic Steam Flow, International communications in heat and mass transfer, 36(9): 902-907. https://doi.org/10.1016/j.icheatmasstransfer.2009.06.001

Nikkhahi B, Shams M, Ziabasharhagh M., 2010, “A Numerical Study of Two-Phase Transonic Steam Flow Through ConvergenceDivergence Nozzles with Different Rates of Expansion," Korean Journal of Chemical Engineering, 27(6): 1646-1653. https://doi.org/10.1016/j.icheatmasstransfer.2009.06.001

Mahpeykar, M. R., Teymourtash, A. R., \& Amiri Rad, E., 2011, "Reducing Entropy Generation by Volumetric Heat Transfer in a Supersonic Two-Phase Steam Flow in a Laval Nozzle," International Journal of Exergy, 9(1), 21-39.

https://doi.org/10.1504/IJEX.2011.041428

Shooshtari S H R, Shahsavand A., 2013, "Reliable Prediction of Condensation Rates for Purification of Natural Gas via Supersonic Separators," Separation and Purification Technology, 116: 458-470. https://doi.org/10.1016/j.seppur.2013.06.009
Dykas S, Wróblewski W., 2011, "Single-and Two-Fluid Models for Steam Condensing Flow Modeling," International Journal of Multiphase Flow, 37(9): 1245-1253. https://doi.org/10.1016/j.ijmultiphaseflow.2011.05.008

Yousif A H, Al-Dabagh A M, Al-Zuhairy R C., 2013, "NonEquilibrium Spontaneous Condensation in Transonic Steam Flow," International Journal of Thermal Sciences, 68: 32-41. https://doi.org/10.1016/j.ijthermalsci.2013.01.002

Menter F. R., 1994, “Two-Equation Eddy-Viscosity Turbulence Models for Engineering Applications," AIAA Journal, Vol. 32(8) :1598-1605. https://doi.org/10.2514/3.12149

Patankar S V, Spalding D B., 1972, "A Calculation Procedure for Heat, Mass and Momentum Transfer in Three-Dimensional Parabolic Flows," International Journal of Heat and Mass Transfer, 15(10): 1787-1806. https://doi.org/10.1016/0017-9310(72)90054-3

Wegener, P. P., Mack, L. M., 1958 , "Condensation in Supersonic and Hypersonic Wind Tunnels ," Advances Applied Mechanics, 5: 307-447. http://dx.doi.org/10.1016/S0065-2156(08)70022-X

Fei, J.Y., Li, Y., Li L., 2008, "Numerical Analysis on the Three -Phase Flow with Condensation of $\mathrm{CH}_{4}, \mathrm{H}_{2} \mathrm{O}$ and $\mathrm{n}-\mathrm{C}_{9} \mathrm{H}_{2} \mathrm{O}$," Journal of Petrochemical Universities, 21(3): 1-4. http://dx.doi.org/10.3936/j.issn.1006-396X.2008.03.001

Yakhot V, Orszag S A, Thangam S, et al., 1992, "Development of Turbulence Models for Shear Flows by a Double Expansion Technique," Physics of Fluids A: Fluid Dynamics, 4(7): 1510-1520. http://dx.doi.org/10.1063/1.858424

Young, J. B., 1988, "An Equation of Status for Vapor for Turbomachinery and Other Flow Calculations," Journal of Engineering for Gas Turbines \& Power, 110(1): 1-7. http://dx.doi.org/10.1115/1.3240080

Labetski D G, Holten V, van Dongen M E H., 2004, "Comment on "The Nucleation Behavior of Supercooled Water Vapor in Helium," Journal of Chemical Physics, 120: 6314. http://dx.doi.org/10.1063/1.1645770

Gyarmathy, G., 1982, "The Spherical Droplet in Gaseous Carrier Stream: Review and Synthesis," Multiphase Science \& Technology, 1(1): 99-279. http://dx.doi.org/10.1615/MultScienTechn.v1.i1-4.20

Lamanna, G., 2000, “On Nucleation and Droplet Growth in Condensing Nozzle Flows," Ph.D. Thesis, Eindhoven University of Technology, Netherlands, 45-59. http://dx.doi.org/10.6100/IR539104 